\title{
Severe hepatocytolisis syndrome - a challenge in medical therapy of Cushing's disease
}

${ }^{1}$ Department of Endocrinology, Iuliu Hatieganu University of Medicine and Pharmacy, Cluj-Napoca, Romania ${ }^{2}$ Department of Endocrinology, Clinical County Hospital, Cluj-Napoca, Romania

${ }^{3}$ Department of Endocrinology, Carol Davila University of Medicine and Pharmacy, Bucharest, Romania \& C.I.Parhon National Institute of Endocrinology, Bucharest, Romania

${ }^{4}$ Department of Radiotherapy, Prof. Dr. Ion Chiricuta Oncology Institute, Cluj-Napoca, Romania

\begin{abstract}
\section{Introduction}

Cushing's disease is a rare endocrine disorder characterized by persistent hypercortisolism due to excessive, autonomous ACTH secretion by a pituitary adenoma. Transsphenoidal adenomectomy is the main therapeutic option in Cushing's disease. When imaging studies are unable to demonstrate an obvious pituitary mass complete tumor resection is difficult and often encumbered by risk of relapse. Medical therapy is a second-line option or the first-line treatment for patients with high surgical risk, incomplete surgical resection or relapse. Rarely classic clinical manifestations limit the selection of medical therapy for Cushing's disease.

\section{Case presentation}

We present the case of a male patient with Cushing's disease complicated with diabetes mellitus and severe hepatocytolisis syndrome with no visible pituitary adenoma on MRI studies. In the absence of technical equipment petrosal sinus sampling could not be performed in order to improve surgery outcome.
\end{abstract}

\section{Mara Carsote}

Bucharest, Romania, Aviatorilor Ave 34-38, sector 1, postal code 011863 fax: +40213170607 ;

phone: +40213172041 ;

email: carsote_m@hotmail.com

\section{Conclusion}

The presence of unbalanced diabetes and severe hepatocytolisis syndrome made it impossible to use steroidogenesis inhibitors (mitotane, ketoconazole, metyrapone, etomidate) or inhibitors of ACTH secretion as pasireotide that represent a new option in achieving control of hypercortisolism.

Keywords: Cushing's disease, hepatic cytolysis, pasireotide

\section{Introduction}

Cushing's disease is a rare endocrine disorder, with an incidence of 1-3 cases per 1 million inhabitants / year, due to excessive cortisol secretion [1]. The most common cause of Cushing's disease is an ACTH-secreting pituitary adenoma. Cushing's disease is rarely the consequence of $\mathrm{CRH}$ secretion [2]. Despite significant improvement of the current treatment methods, Cushing's disease is an important cause of morbidity and mortality mainly due to specific metabolic disturbances caused by persistent hypercortisolism. [1,2,3] Chronic hypercortisolism is associated with increased risk of cardiovascular disease by adding more cardiovascular risk factors: visceral obesity, dyslipidemia, diabetes mellitus, 
hypertension [3]. Visceral obesity and insulin resistance are the major factors responsible for liver damage in patients with Cushing's disease varying from hepatic steatosis to steatohepatitis and steatonecrosis [4]. Transsphenoidal adenomectomy is the principal therapeutic option in Cushing's disease with remission rates ranging from $65-90 \%$ for microadenomas and $50-70 \%$ for macroadenomas. [4] In case of relapse ( $25 \%$ of cases), second-line options include repeat transsphenoidal surgery, radiotherapy, medical treatment with steroidogenesis inhibitors or inhibitors of ACTH secretion and, ultimately, bilateral adrenalectomy. [1,2,3,4,5] Except for bilateral adrenalectomy none of the mentioned therapeutic methods provide effective control of hypercortisolism, with remission rates below 50\% [5]. Severe liver injury offers limited possibilities for drug therapy in patients with Cushing's disease. The presence of a severe hepatocytolisis syndrome in a patient with Cushing's disease and no visible pituitary adenoma on MRI studies without signs of CRH secretion, constitutes a real therapeutic challenge. [5]

\section{Case report}

We present the case of a 40 year-old male admitted for an endocrinological check up of suspected Cushing's syndrome based on a first endocrine control. Later the endocrine tests were performed at Clinical County Hospital from Cluj Napoca, Romania. The suspicion was made because of newly onset central obesity (approximately 12 kilograms weight gain during the previous year) associated with moderately elevated blood pressure, asthenia, fatigue at moderate-to-low effort, insomnia, psycho-emotional lability, peripheral edema. The patient had a history of type II diabetes, diagnosed three months prior to admission, left kidney stones, chronic erythematous gastritis and cholesterolosis of gallbladder. He is a current smoker and he strongly denies any alcohol use.

Physical exam revealed grade I obesity with central distribution, purple abdominal striae, proximal miopathy, acanthosis nigricans of the axillae and palms, diffuse thoracic and abdominal folliculitis, bilateral gynecomastia, umbilical hernia, irregular heartbeat (BP) of $100 /$ minute and blood pressure of 145/95 mmHg.

The hormonal profile revealed high urinary and serum cortisol, with loss of diurnal variation and high ACTH levels. Dynamic tests were strongly suggestive for Cushing's disease: inadequate suppression of serum cortisol after the low-dose Dexamethasone (DXM) test but adequate suppression after the highdose DXM test. (Table I)

Table I: Biochemical and hormonal parameters in 40 year old male patient with clinicaly suspected Cushing's syndrome

\begin{tabular}{|l|l|l|}
\hline Parameter & Value & Reference Range \\
\hline Plasma cortisol 8 a.m. & 27 & $5-25 \mathrm{mcg} / \mathrm{dl}$ \\
\hline Plasma cortisol 8 p.m. & 22.9 & $2.5-13 \mathrm{mcg} / \mathrm{dl}$ \\
\hline $\begin{array}{l}\text { UFC (Urinary Free } \\
\text { Cortisol) }\end{array}$ & 805.9 & $50-190 \mathrm{mcg} / 24 \mathrm{~h}$ \\
\hline $\begin{array}{l}\text { Cortisol } 8 \text { a.m., after 2x2 } \\
\text { DXM }\end{array}$ & 9.94 & $<1.8 \mathrm{mcg} / \mathrm{dl}$ \\
\hline $\begin{array}{l}\text { Cortisol } 8 \text { a.m., after 2x8 } \\
\text { DXM }\end{array}$ & 2.2 & $\begin{array}{l}<50 \% \text { from } \\
\text { basal value }\end{array}$ \\
\hline $\begin{array}{l}\text { ACTH } \\
\text { Adrenocorticotroph } \\
\text { Hormone) }\end{array}$ & 68.26 & $7.2-63.3 \mathrm{pg} / \mathrm{ml}$ \\
\hline Prolactin & 14 & $1.8-17 \mathrm{ng} / \mathrm{ml}$ \\
\hline Plasma total testosterone & 0.73 & $1.8-9 \mathrm{ng} / \mathrm{ml}$ \\
\hline $\begin{array}{l}\text { TSH (Thyroid } \\
\text { Stimulating Hormone) }\end{array}$ & 2.7 & $1-11.5 \mathrm{U} / \mathrm{L}$ \\
\hline FreeT4 & 1 & $0.89-1.76 \mathrm{ng} / \mathrm{dl}$ \\
\hline $\begin{array}{l}\text { Hb A1c (Glycated } \\
\text { Hemoglobin) }\end{array}$ & 10.6 & $4.8-5.9 \%$ \\
\hline ALT & 220 & $<55 \mathrm{U} / \mathrm{L}$ \\
\hline AST & 178 & $5-34 \mathrm{U} / \mathrm{L}$ \\
\hline GGT & 1937 & $12-64 \mathrm{U} / \mathrm{L}$ \\
\hline Amylase & 2432 & $25-125 \mathrm{U} / \mathrm{L}$ \\
\hline Total cholesterol & 226 & $70-105 \mathrm{mg} / \mathrm{dl}$ \\
\hline Triglycerides & 10,034 & $4,000-10,000$ \\
\hline Plasma morning glucose & $<200 \mathrm{mg} / \mathrm{dl}$ \\
\hline Leukocytes & & \\
\hline
\end{tabular}




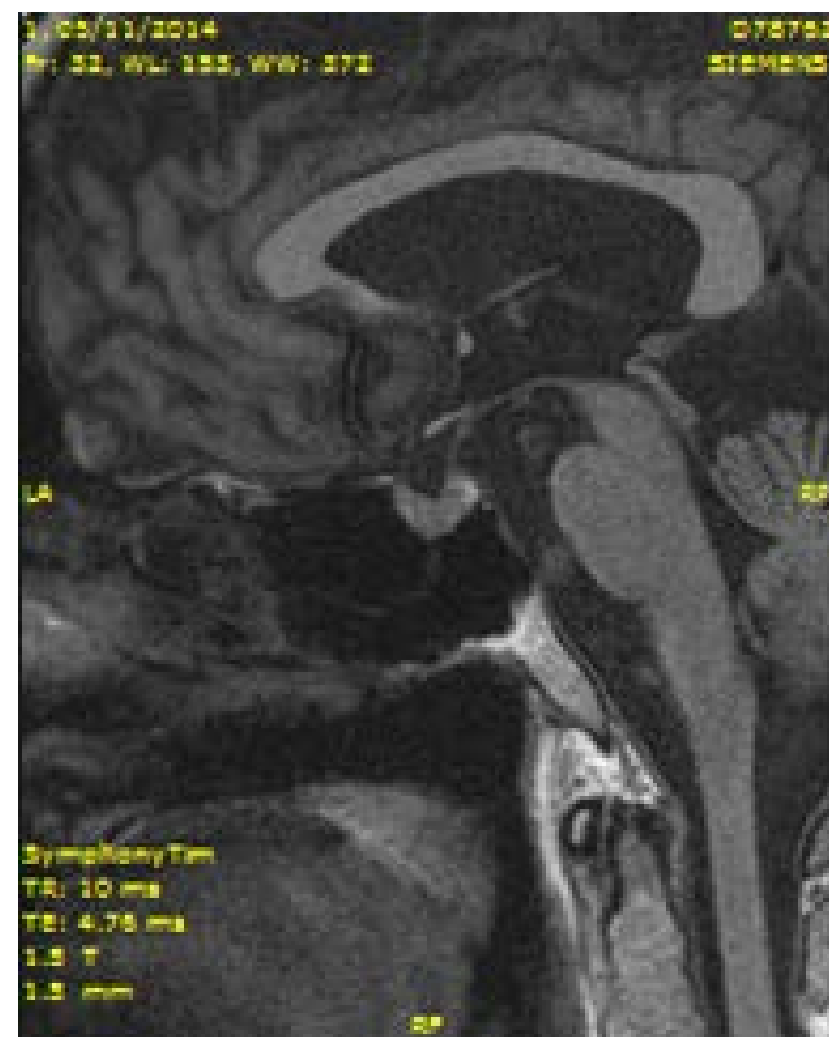

Figure 1. Pituitary MRI: slightly irregular contrast enhancement, without an obvious pituitary mass

No pituitary mass was found at imagery scan. (Figure 1) Thoracic and abdominal CT scan revealed bilateral adrenal hyperplasia, without suspicious nodular lesions in lung parenchyma. (Figure 2)

In the absence of technical equipment petrosal sinus sampling with ACTH measurement could not be performed.

Biochemistry showed severe hepatocytolisis syndrome with markedly elevated GGT, dyslipidemia, inadequate glycemic control, lymphopenia and leukocytosis with neutrophilia. (Table I)

Initial treatment was aimed at correcting these metabolic imbalances: obtaining glycemic control through diet and oral antidiabetic medication: metformin 2x1000 mg / day, hypolipidemic diet, atorvastatin $20 \mathrm{mg} /$ day, fenofibrate $145 \mathrm{mg} /$ day, with periodic monitoring of liver enzymes, hepatoprotective and antihypertensive therapy.

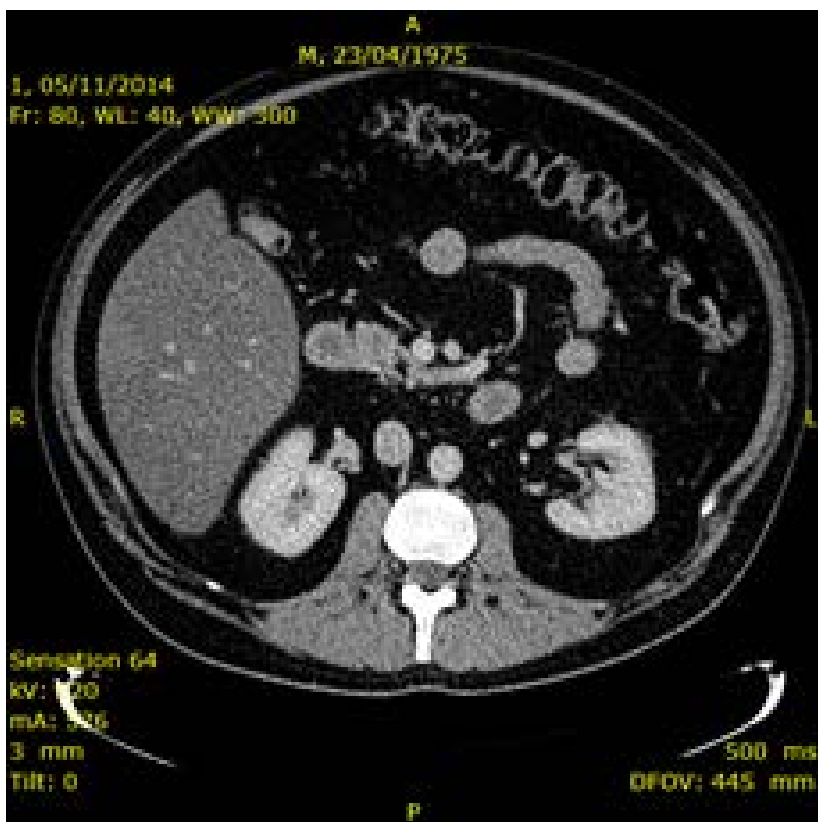

Figure 2. Abdominal CT scan: bilateral adrenal hyperplasia

We recommended curative transsphenoidal surgery although pituitary MRI could not localize the adenoma. The patient refused it.

Given the severe hepatocytolisis syndrome and the presence of unbalanced diabetes mellitus treatment with pasireotide was started but very soon stopped because of already severely damaged metabolic profil. Since the patient refused transsphenoidal surgery the remaining options are pituitary radiation therapy and ultimately, bilateral adrenalectomy. Close follow-up of the patient was recommended.

\section{Discussions}

Cushing's disease is an endocrine disorder characterized by complex clinical manifestations secondary to chronic hypercortisolism. It is associated with increased morbidity and mortality due to specific cardiovascular and metabolic complications such as diabetes mellitus, obesity, hypertension, ischemic stroke, hypercoagulability, decreased resistance to infection. [1,2,3,4,5] Altered lipid metabolism 
is reported in $40-70 \%$ of patients including those with subclinical hypercortisolism. [6] Most studies indicate high cholesterol levels in $25-52 \%$ of pacients with Cushing's disease while hypertriglyceridemia is found in $7-35 \%$ [6]. Our patient presented with mixed hyperlipidemia, with extremely high triglyceride levels, 16 times the reference value.

Liver injury in Cushing's disease varies in intensity, about $20 \%$ of patients presenting with fatty liver on abdominal ultrasound.[7] Severe hepatocytolisis due to steatohepatitis or steatonecrosis rarely occurs. In our case, abdominal ultrasound and CT scan revealed liver steatosis with hepatomegaly (28 $\mathrm{cm}$ in craniocaudal axis). Biochemistry showed severe hepatocytolisis with markedly elevated GGT (30 times the upper limit of normal), highly elevated ALT (4 times the upper limit) and AST (5 times the upper limit) with negative markers for hepatitis B and C.

The main treatment goal in Cushing's disease is to normalize cortisol levels and achieve clinical remission by complete resection of the ACTHsecreting pituitary adenoma, while preserving pituitary function. [5] In this case only MRI showed slightly irregular contrast enhancement baerly suggestive for a pituitary microadenoma.

Pasireotide is an alternative to surgical treatment of Cushing's disease with a direct inhibitory effect on the ACTH-secreting tumor cells. Side effects are largely similar to somatostatin analogues as diarrhea, nausea, biliary sludge and gallstones. [8] Through its effect on pancreatic secretion of insulin and intestinal secretion of glucagon-like peptide-1 the drug commonly induces hyperglycemia [8]. For our patient pasireotide was not an option partly due to the presence of diabetes mellitus with poor glycemic control (HbA1c levels of 10.6\%) and due to severe hepatocytolisis syndrome. In addition the presence of severe hepatocytolisis makes it impossible to use steroidogenesis inhibitors such as ketoconazole which is currently unavailable in our country. Given the patient's refusal of surgery the only remaining alternative is radiation therapy classically reserved for persistent or recurrent forms of hypercortisolism, after surgical treatment. Its main limitations are the delayed onset of effects as 3-10 years after exposure, and aditive risk of pituitary insufficiency.

\section{Conclusion}

The presence of both severe hepatocytolisis and uncontrolled secondary diabetes mellitus in a patient with Cushing's disease who refused pituitary surgery represents an extremely dificult chalange in managing the appropriate therapy in order to obtain the disease control.

\section{Acknowledgement}

We thank to the patient for giving us the informed written consent.

\section{References}

1. Pivonello, R., De Martino, M. C., De Leo, M., Lombardi, G., \& Colao, A. (2008). Cushing's Syndrome. Endocrinol Metab Clin North Am. 37(1), 135-149, ix. doi: 10.1016/j. ecl.2007.10.010

2. Newell-Price, J., Bertagna, X., Grossman, A. B., \& Nieman, L. K. (2006). Cushing's syndrome. Lancet. 367(9522), 1605-1617. doi: 10.1016/ s0140-6736(06)68699-6

3. Poullot, A-G \& Chevalier, N. (2013).New options in the treatment of Cushing's disease: a focus on pasireotide. Research and Reports in Endocrine Disorders. 3,31-38.

4. Rockall, A. G., Sohaib, S. A., Evans, D., Kaltsas, G., Isidori, A. M., Monson, J. P., Besser, G.M., Grossman, A.B. \& Reznek, R. H. (2003). Hepatic steatosis in Cushing's syndrome: a radiological assessment using computed tomography. Eur $J$ Endocrinol. 149(6), 543-548. 
5. Biller, B. M., Grossman, A. B., Stewart, P. M., Melmed, S., Bertagna, X., Bertherat, J., Buchfelder, M.,Colao, A.,Hermus, A. R.,Hofland, L.J., Klibanski, A., Lacroix, A., Lindsay, J.R., Newell-Price, J., Nieman, L.K., Petersenn, S., Sonino, N., Stalla, G.K., Swearingen, B., Vance, M..L, Wass, J. \& A H Boscaro, M. (2008). Treatment of adrenocorticotropin-dependent Cushing's syndrome: a consensus statement. J Clin Endocrinol Metab. 93(7), 2454-2462. doi: 10.1210/jc.2007-2734

6. Greenman Y. (2010). Management of dyslipidemia in Cushing's syndrome. Neuroendocrinology. 92,91-95.

7. Falck-Ytter, Y., Younossi, Z.M., Marchesini, G. \& McCullough, A.J. (2001) Clinical features and natural history of nonalcoholic steatosis syndromes. Seminars in Liver Disease. 21,1726.

8. Lacroix, A. \& Pivonello, R. (2012). Medical treatment of Cushing's disease with pasireotide. European Endocrinology. 99-104. 